\title{
Reference End Time Point End
}

National Cancer Institute

\section{Source}

National Cancer Institute. Reference End Time Point End. NCI Thesaurus. Code C82574.

A point in time that indicates the cessation of an event. 